\title{
Expression of Serum- and Glucocorticoid-Inducible Kinase Is Regulated in an Experience-Dependent Manner and Can Cause Dendrite Growth
}

\author{
Samuel David, ${ }^{1 *}$ Susan L. Stegenga, ${ }^{1 *}$ Peter Hu, ${ }^{1}$ Guoxiang Xiong, ${ }^{1}$ Elizabeth Kerr, ${ }^{2}$ Katherine B. Becker, ${ }^{3}$ \\ Sumathi Venkatapathy, ${ }^{2}$ Janet A. Warrington, ${ }^{2}$ and Robert G. Kalb ${ }^{1}$ \\ ${ }^{1}$ Department of Neurology, Children's Hospital of Philadelphia, Philadelphia, Pennsylvania 19104, ${ }^{2}$ Affymetrix, Santa Clara, California 95051, and ${ }^{3}$ Applied \\ Biosystems, Foster City, California 94404
}

\begin{abstract}
The interaction of an animal with its environment during a critical period in early postnatal life has lifelong effects on the structure and function of sensory and motor systems. To gain insight into the molecular mechanisms of experience-dependent development, we challenged young rats to adapt to a new environment that engenders novel motor behavior. Rats born in the gravitational field $(1 G)$ of the earth subsequently were reared for 2 weeks either in the absence of gravity (microgravity) or at $1 G$. A comparison of gene expression using microarrays led to the identification of a panel of differentially regulated transcripts. We report here that the abundance of serum- and glucocorticoid-inducible kinase (SGK) is increased in spinal cord tissue from animals reared in microgravity in comparison with 1Greared controls. The induction of SGK expression also can be achieved by administration of glucocorticoids to animals at $1 G$ or neurons in vitro. Expression of constitutively active SGK in neurons leads to the elaboration of neuronal dendrites and their branching. Glucocorticoids also lead to dendrite elaboration, and this effect can be abrogated by inhibiting SGK activity. Changes in the level of expression of SGK could be part of the mechanism for experience-dependent acquisition of mature neuronal properties.
\end{abstract}

Key words: dendrite; locomotion; plasticity; spinal cord; SGK; motor neuron

\section{Introduction}

During a critical period in early postnatal life (Hensch, 2004), the environment in which an animal is reared can influence the structural, electrophysiological, and molecular properties of developing neurons (Goodman and Shatz, 1993; Albright et al., 2000; Zhang and Poo, 2001). At the cellular level, the experiencedependent development involves, in part, the selective growth and stabilization of specific synapses and the elimination of others (Constantine-Paton et al., 1990). The driving force for these phenomena involves the environmentally evoked level and pattern of synaptic activity (Shatz, 1990).

Experience-dependent development of locomotor behavior has been shown in a number of experimental systems (Walton et al., 1992, 2005a,b). Although neurons at every level of the neuroaxis participate in locomotor function, for several reasons, we

Received Jan. 3, 2005; revised June 9, 2005; accepted June 9, 2005.

This work was supported by National Institutes of Health Grants NS 33467 and NS 29837 and NASA Grant NAG2-951. We are indebted to the crew of Neurolab (STS-90) for their superb care of animals during microgravity, Dr. Rachael Neve for packaging the recombinant HSVs, and Dr. Gary Firestone for providing the anti-SGK antibody. We gratefully acknowledge the generous gift of Oligotex Mini mRNA and RNeasy mini kits from K. Malloy (Qiagen, Valencia, (A) and Superscript II RT, RNaseH DNA ligase, polymerase I, and T4 polymerase from D. Consiglio (Invitrogen, Gaithersburg, MD).

*S.D. and S.L.S. are co-first authors.

Correspondence should be addressed to Dr. Robert G. Kalb, Children's Hospital of Philadelphia Abramson

Research Center \#814, 3615 Civic Center Boulevard, Philadelphia, PA 19104. E-mail: Kalb@email.chop.edu.

S. L. Stegenga's present address: Vysis, 3100 Woodcreek Drive, Downers Grove, IL 60515.

D0I:10.1523/JNEUROSCI.0006-05.2005

Copyright $\odot 2005$ Society for Neuroscience $\quad$ 0270-6474/05/257048-06\$15.00/0 focused attention on the spinal cord elements. Spinal cord circuitry plays a central role in organizing rhythmic alternating limb movements (Cazalets et al., 1996), can learn motor tasks, and will retain this information for prolonged periods (Lovely et al., 1990). Use-dependent remodeling of spinal cord circuitry occurs. For example, a comparison of animals reared in two different environments necessitating distinct locomotor function [the absence of gravity (microgravity) vs gravitational field of the earth $(1 G)]$ demonstrated experience-dependent development of motor neuron dendritic architecture (Kalb, 1994; Inglis et al., 2000). To identify genes that might subserve this developmental plasticity, we analyzed the effect of rearing environment (microgravity vs $1 G$ ) on spinal cord gene expression.

\section{Materials and Methods}

Animals. The 8- and 13-d-old Sprague Dawley rats were launched aboard the NASA Neurolab space shuttle (STS-90) and lived for $16 \mathrm{~d}$ in microgravity (Inglis et al., 2000). Details of animal selection, breeding, husbandry, and in-flight health have been described previously (Inglis et al., 2000; Stegenga et al., 2003). Tissues from flight animals (FLT) were obtained for analysis within $12 \mathrm{~h}$ of shuttle landing when the lysates were made. Tissues from the two sets of age-matched control animals were collected in the same manner as the FLT tissue.

Microarrays. At the commencement of this study, there was limited rat sequence information publicly available. Therefore, to study the maximum number of rodent genes, we probed a microarray that consisted mostly of mouse sequences; rat sequences were $<5 \%$. To adjust for differences in signal intensity for each array, we normalized samples by using $\beta$-actin and glyceraldehyde phosphate dehydrogenase (GAPDH) 
intensity levels. The details of the probe generation, the specific microarrays used, and the data analysis are described in the supplemental material (available at www.jneurosci.org).

Quantitative reverse transcription-PCR. Candidate gene sequences from the GeneChip (Affymetrix, Santa Clara, CA) probe array expression study were analyzed to generate sequence specific primers and probes for TaqMan. The details of probes used in this study, RNA/cDNA preparation, and the methods for quantitative analysis are described in the supplemental material (available at www.jneurosci.org).

Amplification plots were generated to determine the threshold cycle $(C t)$. The $C t$ value for all gene targets was normalized to the $C t$ value of GAPDH and relative to a calibrator to generate a comparative $C t$ value $(\Delta \Delta C \mathrm{t})$ for each sample. Analysis comparing FLT and control samples was performed by using the fold difference value.

Immunological analysis of FLT and control spinal cord tissue. After homogenization in Trizol (Invitrogen, San Diego, CA) and extraction of RNA, the DNA and protein were extracted from the spinal cord samples as recommended by the vendor. The details of immunoblot procedures and quantitative analysis are described in the supplemental material (available at www.jneurosci.org). Immunohistological techniques have been described previously (Jakowec et al., 1995; Stegenga et al., 2003).

In vivo studies of serum- and glucocorticoid-inducible kinase. Postnatal day 25 (P25) Sprague Dawley rats received a subcutaneous injection of corticosterone ( $4 \mathrm{mg} / 100 \mathrm{~g}$ in sesame oil) or vehicle. Then, $2 \mathrm{~h}$ later, the spinal cord tissue was isolated, and lysates were subjected to Western blot analysis.

In vitro studies of serum- and glucocorticoid-inducible kinase. Mixed spinal cord cells were grown on a confluent astrocyte monolayer and supported with glial-conditioned media (Ye and Sontheimer, 1998). The materials used in generating spinal cord cultures and subsequent immunocytological analysis are described in the supplemental material (available at www.jneurosci.org).

Cell culture and transfection. Mixed spinal cord neurons were grown for $2 \mathrm{~d}$ before being transfected with Lipofectamine 2000 according to the manufacturer's protocol (Invitrogen). At $5 \mathrm{~d}$ in vitro (5 DIV), the cells were fixed with $4 \%$ paraformaldehyde, immunostained for mitogen-activated protein2/green fluorescent protein/serum- and glucocorticoid-inducible kinase (MAP-2/GFP/SGK), and visualized by using either fluorescence or the $\beta$-galactosidase reaction. $\beta$-Galactosidase-stained neurons were traced by using computer-assisted camera lucida software (Neurolucida; MicroBrightField, Williston, VT) as described previously (Inglis et al., 1998, 2000, 2002; Gazula et al., 2004). Then, three to six neurons were traced per independent condition from any given in vitro preparation of neurons, and an average was derived. Average values from four to five separate experiments were the basis of the subsequent statistical analysis. The total number of traced neurons included in the analysis displayed in Figure 3 was dominantnegative-SGK (D-N-SGK; $n=25$ ), LacZ (also known as $\beta$-galactosidase; $n=23$ ), and constitutively active-SGK (CA-SGK; $n=22)$ and in Figure 4 was dexamethasone plus D-N-SGK $(n=19)$, dexamethasone plus LacZ $(n=19)$, and vehicle plus LacZ $(n=19)$. Groups of neurons were compared statistically with ANOVA (SAS Institute, Cary, NC), using the harmonic mean to create $F$ values because of variable group sizes. Post hoc comparisons between groups were made by using Scheffé's test, with significance set at $p<0.05$.

Generation of recombinant herpes simplex viruses. The cDNA for D-NSGK or CA-SGK was cloned into the PRPUC amplicon vector and used to generate recombinant virus as described previously (Neve et al., 1997; David and Kalb, 2005). The titer of virus used in these studies was $3-5 \times$ $10^{7} \mathrm{pfu} / \mathrm{ml}$.

\section{Results}

Rats were reared in the gravitational field of the earth until P8 or P13 before being launched on the space shuttle and spending the next $16 \mathrm{~d}$ in microgravity. These young animals (termed FLT) were compared with two control groups who developed at $1 G$ [reared in standard vivarium cages, VIV; reared in cages similar to those on board the shuttle, asynchronous ground control (AGC)]. In-depth behavioral studies comparing the effects of these rearing environments are described in separate publications (Walton et al., 2005a,b).

On a mouse cDNA microarray, $\sim 10 \%$ of the 6500 genes was detected (called positive), using labeled probes derived from rat spinal cord tissue. A subset of genes was expressed at higher levels in FLT versus control animals within each age group. In this subgroup, using 24-d-old tissues, there was a $3.3 \pm 0.9$-fold increase in FLT versus AGC and $4.2 \pm 1.6$-fold increase in FLT versus VIV. Using P29 tissues, we found there was a $3.5 \pm 1.1$ fold increase in FLT versus AGC and a $3.4 \pm 0.9$-fold increase in FLT versus VIV. Of genes demonstrating at least a twofold change in intensity, transcript levels of nine were examined by TaqMan quantitative reverse transcription-PCR (RT-PCR). Among these candidate genes, we focused on one called SGK for two reasons: (1) the abundance of this transcript (monitored by TaqMan) was elevated in every microgravity tissue sample $(n=8)$ in comparison with controls, and (2) this transcript underwent the largest increase expression in comparison with controls. The increase in SGK transcript levels in 24-d-old animals was $3.8 \pm 0.4$-fold (FLT vs VIV) and $3.0 \pm 0.3$-fold (FLT vs AGC). The increase in SGK transcript levels in 29-d-old animals was $4.6 \pm 0.6$-fold (FLT vs VIV) and 3.0-fold \pm 0.4 (FLT vs AGC).

Western blot confirmed that protein levels of SGK also are regulated by the experience of a space shuttle mission (Fig. 1). SGK immunoreactivity for day 29 FLT animals was $>4.4$ - and 3.0-fold the levels detected in either the VIV or AGC age-matched animals, respectively. For day 24 FLT animals, the SGK immunoreactivity was 3.8- and 3.0-fold higher compared with VIV and AGC age-matched animals. These data corroborate the SGK mRNA results collected by both GeneChip analysis and TaqMan RT-PCR.

Immunohistological examination of spinal cord sections from 29-d-old spinal cord slices was undertaken to identify the putative cell type or types expressing SGK (Fig. 1). Immunostaining revealed the expression of SGK within many large multipolar cells scattered throughout the spinal gray matter; large angulated cells residing within the ventral horn are likely to be motor neurons.

In a mammary epithelial cell line, SGK message and protein can be induced by exposure to the synthetic glucocorticoid dexamethasone (Webster et al., 1993b). We inquired whether glucocorticoids similarly could induce SGK expression in the CNS of animals. At $2 \mathrm{~h}$ after administration of corticosterone to P25 rats, there was a marked induction in SGK in comparison with vehicle-injected animals (Fig. 2). To determine whether the same effects of glucocorticoids could be achieved in spinal cord neurons in vitro, we generated cultures of dissociated spinal cord neurons from embryonic day 15 (E15) rats and stimulated them with dexamethasone or vehicle. Baseline levels of SGK in our cultures were below the level of detection of our assay system, and glucocorticoids led to a pronounced induction of SGK at 2 and $4 \mathrm{~h}$ after drug administration (Fig. 2). To determine the cell type in which dexamethasone induces SGK expression, we immunostained cultures for cell type markers (MAP-2, neurons; GFAP, astrocytes) and found that dexamethasone induced SGK expression exclusively in neurons (Fig. 2).

In addition to induction of SGK, prolonged rearing of young animals in microgravity leads to restructuring of motor neuron dendritic architecture (Inglis et al., 2000). If these two events are linked, one might anticipate that SGK expression would have measurable effects on the morphology of neurons. To examine this issue, we introduced forms of SGK that operate in a CA or D-N manner (Maiyar et al., 1997; Lang et al., 2000; Brunet et al., 2001; David and Kalb, 2005) (or a control vector) into spinal 

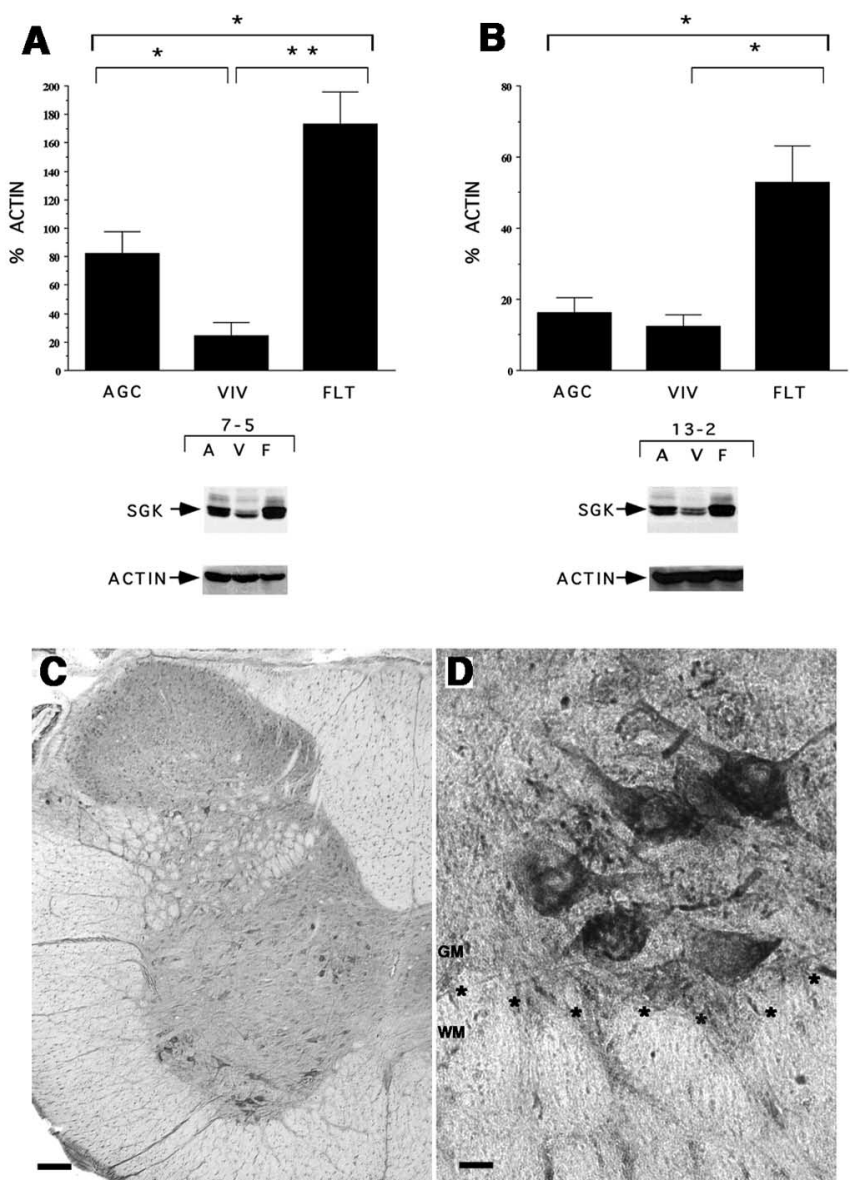

Figure 1. Identification of SGK induction during the STS-90 Neurolab Space Flight Mission. $\boldsymbol{A}$, Protein expression for SGK relative to $\beta$-actin levels for 7-5 age group. $\boldsymbol{B}$, Protein expression for SGK relative to $\beta$-actin levels for the $13-2$ age group. Error bars indicate $\pm \mathrm{SEM} ;{ }^{*} p<0.05$; ${ }^{* *} p<0.01$. Representative Western blot is shown below each bar graph. C, Immunohistology for SGK from 29-d-old rat spinal cord. Immunostaining is seen in a small number of neurons throughout the spinal cord, but most immunostaining is in Rexed lamina IX where motor neurons reside. Scale bar, $100 \mu \mathrm{m}$. D, Higher-magnification view of the ventralmost portion of the spinal gray matter. The gray matter/white matter (GM/WM) border is delineated by asterisks. The large multipolar-immunostained cells are motor neurons. Scale bar, $25 \mu \mathrm{m}$.

neurons in vitro and undertook a quantitative morphometric analysis (Fig. 3). Neuronal expression of CA-SGK led to a significant increase in primary dendrites and dendritic branch points in comparison with neurons expressing LacZ and D-N-SGK. The cell soma of D-N-SGK-expressing neurons was larger than the LacZ control and CA-SGK-expressing neurons. Groups did not differ in terms of the length of the longest dendrite or the overall tree. Thus, increases in SGK activity stimulate select aspects of neuronal dendrite growth.

Because the abundance of SGK is increased by glucocorticoids, we were interested in examining the potential role of SGK in glucocorticoid-induced alterations in neuronal morphology (Fig. 4). A 3 d treatment of neurons with dexamethasone led to an increase in primary dendrites and increased branching of the dendritic tree in comparison with controls, although not affecting the overall size of the tree or the extent of the longest dendrite. Expression of D-N-SGK prevented the dexamethasone effect, and there were no statistically significant differences between vehicle-treated cultures and cultures in which D-N-SGKexpressing neurons were stimulated with dexamethasone.

The MAP kinase (MAPK) and phosphatidylinositol 3' kinase $\left(\mathrm{PI} 3^{\prime} \mathrm{K}\right)$ signaling cascades have been implicated in dendrite
In Vivo

In Vitro

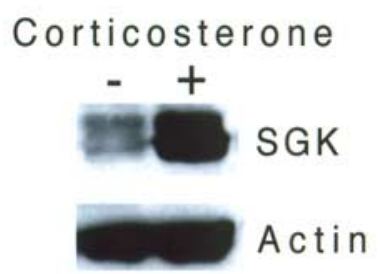

Dexamethasone

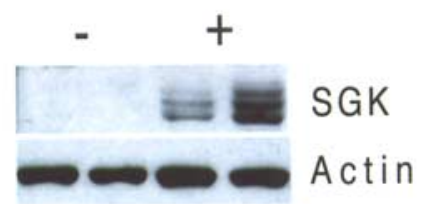

$2 \mathrm{~h} \quad 4 \mathrm{~h} \quad 2 \mathrm{~h} \quad 4 \mathrm{~h}$

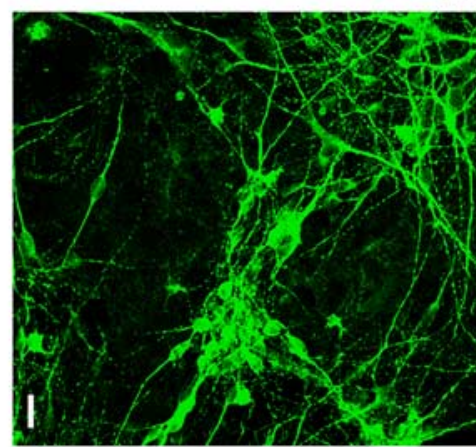

MAP-2

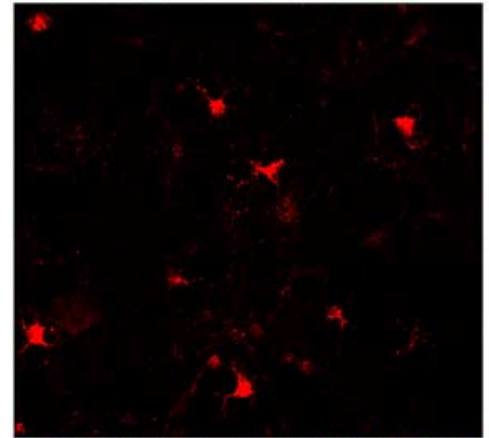

SGK

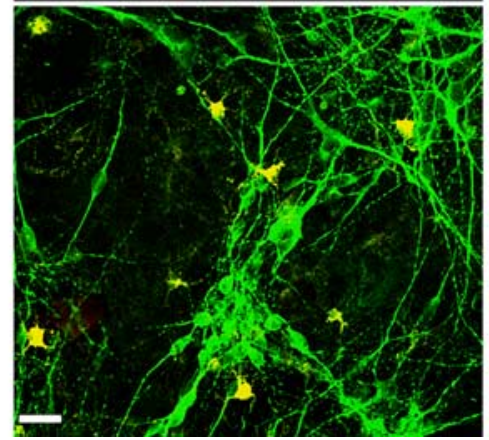

Merge

Figure 2. Corticosteroid induction of SGK in neurons. The top left panel shows immunoblots for SGK or $\beta$-actin of spinal cord lysates from P25 animals given corticosterone or vehicle. Corticosteroid treatment led to an approximately sixfold induction of SGK protein in the spinal cord. The top right panel shows immunoblots for SGK or $\beta$-actin of spinal cord neurons grown in vitro that were treated with dexamethasone or vehicle. Below are images of spinal cord cultures treated with dexamethasone and stained immunocytologically for MAP-2 and SGK (labeled). Corticosteroid treatment led to the induction of SGK expression specifically in neurons (Merge). Scale bar, $45 \mu \mathrm{m}$.

growth (Dijkhuizen and Ghosh, 2005). To determine whether SGK influences the state of activation of these pathways, we generated recombinant herpes simplex virus (HSV) that expresses CA-SGK, D-N-SGK, or LacZ. Spinal cord cultures were infected with these viruses; $24 \mathrm{~h}$ later, lysates were prepared, and immunoblotting was performed (supplemental Fig. 5, available at www. jneurosci.org as supplemental material). The abundance of MAPK and its activated phospho form was the same in cultures infected with HSV-CA-SGK, HSV-D-N-SGK, or HSV-LacZ. 

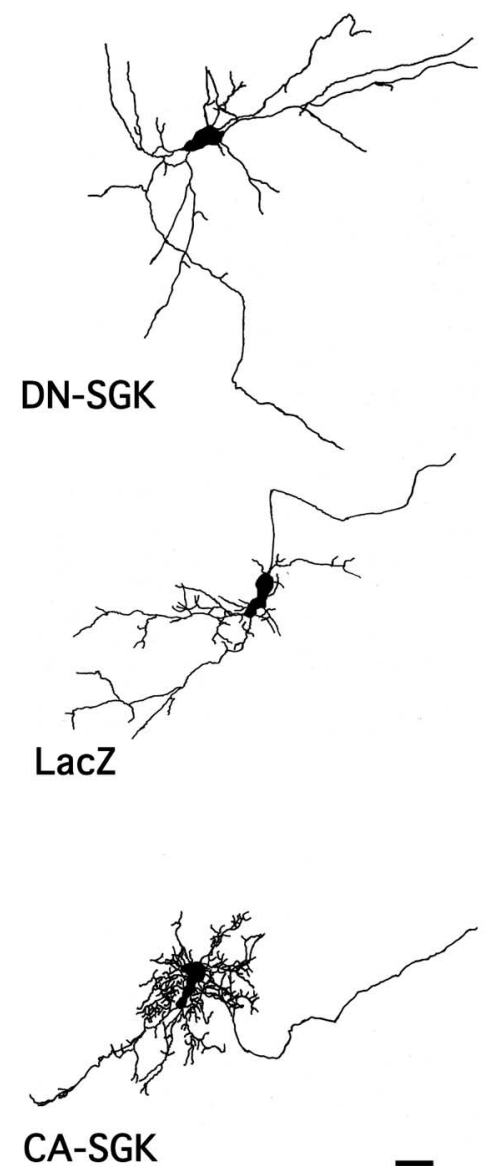

$\begin{array}{lllll} & \text { DN-SGK } & \text { LacZ } & \text { CA-SGK } & \text { F } \\ 1^{\circ} \text { dendrites } & 6.3 \pm 0.5 & 9.3 \pm 1.0 & 16.9 \pm 1.5^{* \dagger} & 27.912 \\ \text { Branches, \# } & 44.8 \pm 4.5 & 80.5 \pm 13 & 177 \pm 19^{* \dagger} & 29.269 \\ \text { Soma area } & 238 \pm 14^{*} & 189 \pm 9 & 176 \pm 7 \dagger & 8.231 \\ \text { Long. dend. } & 205 \pm 21 & 165 \pm 24 & 153 \pm 50 & 0.729 \\ \text { Sarbor size } & 1122 \pm 124 & 988 \pm 92 & 1431 \pm 123 & 3.493 \\ & & & \\ & & & \\ \text { *-significantly different from LacZ, } & & \\ & & \end{array}$

Figure 3. Quantitative analysis of spinal cord neuron dendrites expressing D-N-SGK, CASGK, or $\beta$-galactosidase (LacZ). Values are the means \pm SEM. There was a statistically significant increase in the number of primary dendrites and branches in the CA-SGK-expressing neurons compared with the D-N-SGK-expressing or LacZ-expressing neurons. Representative camera lucida drawings of neurons are shown above the table. Scale bar, $25 \mu \mathrm{m}$.

Similarly, the abundance of $\alpha$-kinase murine thymoma (AKT) and its activated phospho form (a downstream reporter of $\mathrm{PI}^{\prime} \mathrm{K}$ activity) was the same under the three conditions. Glycogen synthase kinase $3 \alpha(\mathrm{GSK} 3 \alpha)$ is a bona fide SGK target (Sakoda et al., 2003; David and Kalb, 2005), and expressing CA-SGK in neuronal culture led to an increase in the abundance of phosphoGSK $3 \alpha$, but not GSK3 $\alpha$ itself. The D-N-SGK did not reduce the baseline level of activation of this kinase.

\section{Discussion}

The environment in which an animal lives can influence the structural, electrophysiological, and molecular properties of the nervous system, and this plasticity is most robust during a brief period in early postnatal life. To identify genes potentially involved in this process, we reared animals in two environments ( $1 G$ vs microgravity) and performed a comparative microarray study. These two rearing environments led to distinct behavioral

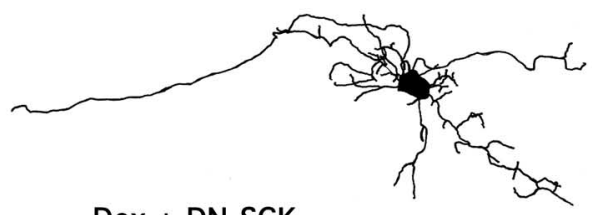

Dex + DN-SGK
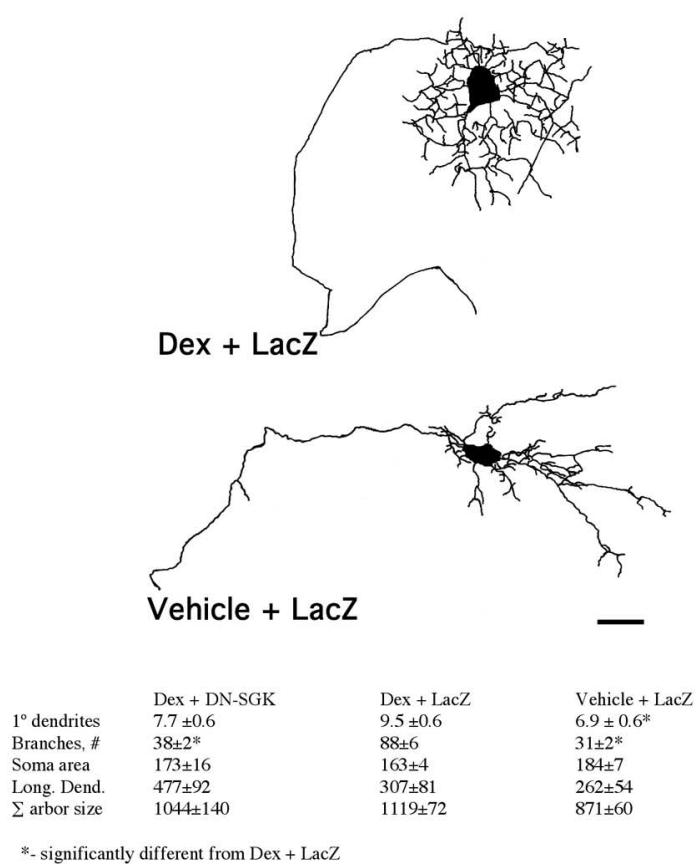

*- significantly different from Dex + LacZ

Figure 4. Quantitative analysis of spinal cord neuron dendrites treated with dexamethasone or vehicle and expressing either D-N-SGK or LaCZ. Values are the means \pm SEM. Dexamethasone led to a statistically significant increase in primary dendrites and branching in comparison with vehicle-treated cultures. Expression of D-N-SGK in neurons blocked the dexamethasone effect on primary dendrite number and branching. Vehicle-treated neurons were statistically indistinguishable from dexamethasone-treated D-N-SGK-expressing neurons. Representative camera lucida drawings of neurons are shown above the table. Scale bar, $35 \mu \mathrm{m}$.

repertoires (Walton et al., 2005a,b) and significant differences in neuroanatomy (Inglis et al., 2000). The present studies provide evidence that SGK is a candidate plasticity gene.

Several technical issues need examining before a discussion of SGK. First, the microarray analysis was performed on RNA that was isolated from spinal cord tissue of FLT animals within $12 \mathrm{~h}$ of the landing of the space shuttle. The degree to which microgravity itself versus other environment factors (noise, stress of landing, postlanding cage handling, etc.) contributes to gene induction cannot be established definitively. A second issue relates to the use of mouse microarrays probed with RNA from rat tissues. This was unavoidable because at the time of this study rat cDNA microarrays did not exist. Because we hybridized mouse arrays with rat probes, we have information on only a subset of potential candidate plasticity genes.

In these studies, we find that SGK mRNA and protein levels were increased in FLT animal spinal cord samples in response to conditions of the STS-90 mission. SGK, a serine/threonine protein kinase with sequence similarity to AKT (also called protein kinase B), was identified originally on the basis of its transcriptional upregulation in vitro in response to glucocorticoids and serum (Webster et al., 1993a). In vitro studies indicate that, in addition to serum and/or glucocorticoids, the transcription of SGK also is influenced by hormones such as follicle-stimulating 
hormone (FSH) (Alliston et al., 2000) and aldosterone (Chen et al., 1999), injury (Imaizumi et al., 1994), cell volume changes (Waldegger et al., 1997; Bell et al., 2000), and heparin (Delmolino and Castellot, 1997). One possibility is that stress accompanying launching, prolonged existence in microgravity, and/or landing could produce elevated glucocorticoid levels (Macho et al., 1993; Stein et al., 1999) and thereby induce SGK expression. Another possibility is that extracellular fluid shifts occurring during space flight may provide the osmotic stimuli for SGK induction.

What are the physiological consequences of increased SGK within neurons of microgravity-reared animals? Because the dendritic architecture of spinal motor neurons in flight animals is distinctly different from that elaborated by motor neurons in ground-based control animals (Inglis et al., 2000), we asked whether SGK could lead to remodeling of neuronal dendrites. Our in vitro data argue in favor of this notion because overexpressing a constitutively active form of SGK in spinal neurons led to a doubling of the number of primary dendrites and the number of dendritic branches in comparison with control neurons. These in vitro observations contrast with our previous findings that motor neurons from microgravity-reared animals have a smaller and less branched dendritic tree than in control animals. These two studies, however, are not directly comparable because the analysis of motor neuron dendrites used FLT tissue, whereas the in vitro studies with CA-SGK or D-N-SGK constructs used neurons from dissociated spinal cords (of which motor neurons are likely to be $\sim 0.1-1.0 \%$ of the total cell population). This raises the possibility that different neuronal populations (motor neurons vs other spinal cord neurons) respond to the effects of SGK is a distinct manner.

Another possible explanation for the differences between the in vitro and in vivo observations on dendrites may relate to the effects of glucocorticoids. Chronic treatment of animals with glucocorticoids leads to atrophy of hippocampal neuron dendrites (Woolley et al., 1990; Magarinos and McEwen, 1995). Because serum glucocorticoids may be elevated for a substantial period of time during microgravity (Macho et al., 1993), susceptible neurons may undergo dendrite atrophy throughout the neuroaxis. The upregulation of SGK expression in spinal cord neurons might counter this effect and act to maintain the dendritic arbor in the setting of systemic stress. Subpopulations of neurons may be distinguished by their glucocorticoid-evoked SGK expression as well as their intrinsic responsiveness to the dendrite atrophypromoting action of glucocorticoids.

The molecular events downstream of SGK that result in dendrite growth are not known but appear unlikely to involve MAPK or AKT directly (supplemental Fig. 5, available at www.jneurosci. org as supplemental material). The alteration in GSK3 $\alpha$ activity (i.e., its state of phosphorylation) is intriguing because a close relative, GSK $3 \beta$, recently has been shown to regulate microtubule assembly and axon morphogenesis (Jiang et al., 2005; Yoshimura et al., 2005). It is noteworthy that BDNF-induced primary dendrite formation in cortical neurons uses the PI $3^{\prime} \mathrm{K}$ signaling pathway (Dijkhuizen and Ghosh, 2005), and PI3' $\mathrm{K}$ is an upstream activator of both AKT and SGK (Kobayashi and Cohen, 1999; Park et al., 1999; David and Kalb, 2005). Finally, because SGK is a cAMP response element-binding protein (CREB) kinase (David and Kalb, 2005) and CREB is known to participate in dendrite morphogenesis (Redmond et al., 2002), this is another potential mechanism by which SGK could evoke dendrite remodeling.

Our microarray study aimed to identify genes that change levels of expression during the process of the young nervous system adapting to a new environment. Identification of SGK targets in CNS tissues from flight animals may yield insight into the (patho)physiological processes incurred during space shuttle missions.

\section{References}

Albright TD, Jessell TM, Kandel ER, Posner MI (2000) Neural science: a century of progress and the mysteries that remain. Neuron [Suppl] 25:S1-S55.

Alliston TN, Gonzalez-Robayna IJ, Buse P, Firestone GL, Richards JS (2000) Expression and localization of serum/glucocorticoid-induced kinase in the rat ovary: relation to follicular growth and differentiation. Endocrinology 141:385-395.

Bell LM, Leong MLL, Kim B, Wang E, Park J, Hemmings BA, Firestone GL (2000) Hyperosmotic stress stimulates promoter activity and regulates cellular utilization of the serum- and glucocorticoid-inducible protein kinase (Sgk) by a p38 MAPK-dependent pathway. J Biol Chem 275:25262-25272.

Brunet A, Park J, Tran H, Hu LS, Hemmings BA, Greenberg ME (2001) Protein kinase SGK mediates survival signals by phosphorylating the Forkhead transcription factor FKHRL1 (FOXO3a). Mol Cell Biol 21:952-965.

Cazalets J-R, Borde M, Clarac F (1996) The synaptic drive from the spinal locomotor network to motoneurons in the newborn rat. J Neurosci 16:298-306.

Chen S-Y, Bhargava A, Mastroberardino L, Meijer OC, Wang J, Buse P, Firestone GL, Verrey F, Pearce D (1999) Epithelial sodium channel regulated by aldosterone-induced protein SGK. Proc Natl Acad Sci USA 96:2514-2519.

Constantine-Paton M, Cline HT, Debski E (1990) Patterned activity, synaptic convergence, and the NMDA receptor in developing visual pathways. Annu Rev Neurosci 13:129-154.

David S, Kalb RG (2005) Serum/glucocorticoid-inducible kinase can phosphorylate the cyclic AMP response element binding protein, CREB. FEBS Lett 579:1534-1538.

Delmolino LM, Castellot JJ (1997) Heparin suppresses $s g k$, an early response gene, in proliferating vascular smooth muscle cells. J Cell Physiol 173:371-379.

Dijkhuizen PA, Ghosh A (2005) BDNF regulates primary dendrite formation in cortical neurons via the PI3-kinase and MAP kinase signaling pathways. J Neurobiol 62:278-288.

Gazula VR, Roberts M, Luzzio C, Jawad AF, Kalb RG (2004) Effects of limb exercise after spinal cord injury on motor neuron dendrite structure. J Comp Neurol 476:130-145.

Goodman CS, Shatz CJ (1993) Developmental mechanisms that generate precise patterns of neuronal connectivity. Cell 10:77-98.

Hensch TK (2004) Critical period regulation. Annu Rev Neurosci 27:549-579.

Imaizumi K, Tsuda M, Wanaka A, Tohyama M, Takagi T (1994) Differential expression of $s g k$ mRNA, a member of the Ser/Thr protein kinase gene family, in rat brain after CNS injury. Brain Res Mol Brain Res 26:189-196.

Inglis FM, Furia F, Zuckerman KE, Strittmatter SM, Kalb RG (1998) The role of nitric oxide and NMDA receptors in the development of motor neuron dendrites. J Neurosci 18:10493-10501.

Inglis FM, Zuckerman KE, Kalb RG (2000) Experience-dependent development of spinal motor neurons. Neuron 26:299-305.

Inglis FM, Crockett R, Korada S, Abraham WC, Hollmann M, Kalb RG (2002) The AMPA receptor GluR1 regulates dendritic architecture of motor neurons. J Neurosci 22:8042-8051.

Jakowec MW, Fox AJ, Martin LJ, Kalb RG (1995) Quantitative and qualitative changes in AMPA receptor expression during spinal cord development. Neuroscience 67:893-907.

Jiang H, Guo W, Liang X, Rao Y (2005) Both the establishment and the maintenance of neuronal polarity require active mechanisms: critical roles of GSK-3 $\beta$ and its upstream regulators. Cell 120:123-135.

Kalb RG (1994) Regulation of motor neuron dendrite growth by NMDA receptor activation. Development 120:3063-3071.

Kobayashi T, Cohen P (1999) Activation of serum- and glucocorticoidregulated protein kinase by agonists that activate phosphatidylinositide 3-kinase is mediated by 3-phosphoinositide-dependent protein kinase-1 (PDK1) and PDK2. Biochem J 339:319-328.

Lang F, Klingel K, Wagner CA, Stegen C, Warntges S, Friedrich B, Lanzendorfer M, Melzig J, Moschen I, Steuer S, Waldegger S, Sauter M, Paul- 
michl M, Risler T, Gamba G, Capasso G, Kandolf R, Hebert SC, Massry SG, Broer S (2000) Deranged transcriptional regulation of cell-volumesensitive kinase hSGK in diabetic nephropathy. Proc Natl Acad Sci USA 97:8157-8162.

Lovely RG, Gregor RJ, Roy RR, Edgerton VR (1990) Weight-bearing hindlimb stepping in treadmill-exercised adult spinal cats. Brain Res 514:206-218.

Macho L, Jezova D, Jurcovicova J, Kvetnansky R, Vigas M, Serova LB (1993) Effect of space flight on the development of endocrine functions in rats. Endocr Regul 27:17-22.

Magarinos AM, McEwen BS (1995) Stress-induced atrophy of apical dendrites of hippocampal CA3c neurons: comparison of stressors. Neuroscience 69:83-88.

Maiyar AC, Phu PT, Huang AJ, Firestone GL (1997) Repression of glucocorticoid receptor transactivation and DNA binding of a glucocorticoid response element within the serum/glucocorticoid-inducible protein kinase (SGK) gene promoter by the p53 tumor suppressor protein. Mol Endocrinol 11:312-329.

Neve RL, Howe JR, Hong S, Kalb RG (1997) Introduction of the glutamate receptor subunit 1 into motor neurons in vitro and in vivo using a recombinant herpes simplex virus. Neuroscience 79:435-447.

Park J, Leong MLL, Buse P, Maiyar AC, Firestone GL, Hemmings BA (1999) Serum- and glucocorticoid-inducible kinase (SGK) is a target of the PI 3-kinase-stimulated signaling pathway. EMBO J 18:3024-3033.

Redmond L, Kashani AH, Ghosh A (2002) Calcium regulation of dendritic growth via CaM kinase IV and CREB-mediated transcription. Neuron 34:999-1010.

Sakoda H, Gotoh Y, Katagiri H, Kurokawa M, Ono H, Onishi Y, Anai M, Ogihara T, Fujishiro M, Fukushima Y, Abe M, Shojima N, Kikuchi M, Oka Y, Hirai H, Asano T (2003) Differing roles of Akt and serum- and glucocorticoid-regulated kinase in glucose metabolism, DNA synthesis, and oncogenic activity. J Biol Chem 278:25802-25807.

Shatz CJ (1990) Impulse activity and the patterning of connections during CNS development. Neuron 5:745-756.

Stegenga SL, Eward W, Kalb RG (2003) Shuttle mission effects on glutamate receptor expression in the developing rodent spinal cord. Aviat Space Environ Med 74:615-621.

Stein TP, Schluter MD, Moldawer LL (1999) Endocrine relationships during human space flight. Am J Physiol 276:E155-E162.

Waldegger S, Barth P, Raber G, Lang F (1997) Cloning and characterization of a putative human serine/threonine protein kinase transcriptionally modified during anisotonic and isotonic alterations of cell volume. Proc Natl Acad Sci USA 94:4440-4445.

Walton KD, Lieberman D, Llinas A, Begin M, Llinas RR (1992) Identification of a critical period for motor development in neonatal rats. Neuroscience 51:763-767.

Walton KD, Harding S, Anschel D, Harris YT, Llinas R (2005a) The effects of microgravity on the development of surface righting in rats. J Physiol (Lond) 565:593-608.

Walton KD, Benavides L, Singh N, Hatoum N (2005b) Long-term effects of microgravity on the swimming behaviour of young rats. J Physiol (Lond) 565:609-626.

Webster MK, Goya L, Ge Y, Maiyar AC, Firestone GL (1993a) Characterization of $s g k$, a novel member of the serine/threonine protein kinase gene family which is transcriptionally induced by glucocorticoids and serum. Mol Cell Biol 13:2031-2040.

Webster MK, Goya L, Firestone GL (1993b) Immediate-early transcriptional regulation and rapid mRNA turnover of a putative serine/threonine protein kinase. J Biol Chem 268:11482-11485.

Woolley CS, Gould E, McEwen BS (1990) Exposure to excess glucocorticoids alters dendritic morphology of adult hippocampal pyramidal neurons. Brain Res 531:225-231.

Ye ZC, Sontheimer H (1998) Astrocytes protect neurons from neurotoxic injury by serum glutamate. Glia 22:237-248.

Yoshimura T, Kawano Y, Arimura N, Kawabata S, Kikuchi A, Kaibuchi K (2005) GSK- $3 \beta$ regulates phosphorylation of CRMP- 2 and neuronal polarity. Cell 120:137-149.

Zhang LI, Poo MM (2001) Electrical activity and development of neural circuits. Nat Neurosci [Suppl] 4:1207-1214. 